\title{
New horizons in pulmonary arterial hypertension management
}

\author{
Vallerie McLaughlin ${ }^{1}$, Gérald Simonneau ${ }^{2,3,4}$, Nazzareno Galiè ${ }^{5}$ and \\ Lewis J. Rubin ${ }^{6}$
}

\begin{abstract}
Affiliations: 'Dept of Internal Medicine, University of Michigan, Ann Arbor, MI, USA. ${ }^{2}$ Université Paris-Sud, Faculté de Médecine, Le Kremlin-Bicêtre, France. ${ }^{3} \mathrm{AP}-\mathrm{HP}$, Centre de Référence de l'Hypertension Pulmonaire Sévère, Département Hospitalo-Universitaire (DHU) Thorax Innovation, Service de Pneumologie et Réanimation Respiratoire, Hôpital de Bicêtre, Le Kremlin-Bicêtre, France. "UMR-S 999, INSERM and Université Paris-Sud, Laboratoire d'Excellence (LabEx) en Recherche sur le Médicament et l'Innovation Thérapeutique (LERMIT), Centre Chirurgical Marie Lannelongue, Le Plessis Robinson, France. ${ }^{5}$ Dept of Experimental, Diagnostic and Specialty Medicine - DIMES, University of Bologna, Bologna, Italy. ${ }^{6}$ Division of Pulmonary and Critical Care Medicine, University of California, San Diego, CA, USA.
\end{abstract}

Correspondence: Vallerie McLaughlin, Division of Cardiovascular Medicine, University of Michigan Health System, Ann Arbor, MI 48109-5853, USA. E-mail: vmclaughaumich.edu

@ERSpublications

Developments in the management of pulmonary arterial hypertension http://ow.ly/BBeqe

Significant developments have been made in the management of pulmonary arterial hypertension (PAH) over the past year. These include an increased understanding of the need for earlier detection and treatment, changing disease characteristics, the continuing development of new treatment options and an increasing perception of the specific challenges that patients with PAH face at each stage of illness. Notably, an updated treatment algorithm from the 5th World Symposium on Pulmonary Hypertension has been published [1], reflecting recent changes in available evidence. The articles in this issue of the European Respiratory Review encompass the breadth of these issues and are based on presentations from the 13th International Pulmonary Hypertension Forum held in April 2014 in Lisbon, Portugal. These articles not only provide a snapshot of the current understanding but also offer a forward-looking view to new horizons in PAH management.

Progressive failure of the right ventricle due to increased pulmonary vascular resistance is a significant cause of morbidity and mortality in patients with PAH. In the article by NAEIJE and MANES [2], the measurement and pathobiology of the interaction between the right ventricle and the arterial system, the role of diastolic function, and the influence of the left ventricle function on right ventricular activity are discussed.

In examining the clinical and disease characteristics of patients living with $\mathrm{PAH}$, the historical importance of registry data cannot be overstated. As the body of evidence from registries continues to build, it offers a window into changes in patient populations and characteristics over time. In the article by HoEPER and GibBs [3], new trends in PAH demographics and patient subsets, the reasons for these changes, and the potential implications for disease management are identified.

Children with PAH are another distinct subset of patients requiring a tailored approach to diagnosis and treatment $[4,5]$. Treatment of PAH in children is particularly challenging due to difficulties of evaluating treatment efficacy in appropriately designed clinical trials and the limited evidence currently available for PAH drugs in this population. In the article by BEGHETTI and BERGER [6], these challenges are discussed in the context of current options for disease classification, available data from registries and clinical trials, and the authors' own clinical experience.

Received: Aug 292014 | Accepted: Sept 012014

Conflict of interest: Disclosures can be found alongside the online version of this article at err.ersjournals.com

Provenance: Publication of this peer-reviewed article was sponsored by Actelion Pharmaceuticals Ltd, Allschwil, Switzerland (principal sponsor, European Respiratory Review issue 134).

Copyright CERS 2014. ERR articles are open access and distributed under the terms of the Creative Commons Attribution Non-Commercial Licence 4.0. 
While historically, combination therapy has been widely used in PAH management, support for this use has been primarily based on expert opinion, registry data or prior clinical experience. However, as evidence from clinical trials and real-world data increase, it provides a new context in which the role and importance of combination therapy must be re-evaluated. A recent example of this change is reflected in the change in recommendation grade for sequential combination therapy in the updated treatment algorithm [1], which is a result of trials such as SERAPHIN (Study with an Endothelin Receptor Antagonist in Pulmonary Arterial Hypertension to Improve Clinical Outcome) [7] and PATENT-1 (Pulmonary Arterial Hypertension Soluble Guanylate Cyclase-Stimulator Trial 1) [8]. The article by GHOFRANI and HumberT [9] offers a comprehensive summary of the latest available data in combination therapy, and the resultant insights and implications for current and future treatment.

The use of upfront combination therapy is now recommended in patients who are in World Health Organization functional class III/IV, albeit with a lower level of recommendation than monotherapy and sequential combination therapy [1]. A recent pilot study showed promise in a small group of patients with severe PAH $[10,11]$. This treatment approach, and the multifaceted reality of treating severe PAH, is the focus of a case-based review by SITBON [12], which charts the progress of a patient with severe PAH associated with mixed connective tissue disease who received upfront triple combination therapy for PAH along with immunosuppresive therapy.

The successful treatment of patients with severe PAH requires both timely treatment changes (in the form of transitioning to intravenous or subcutaneous pharmacotherapy in response to disease worsening) and managing the transition, when necessary, to lung transplantation. This requires knowledge of the treatments available to patients with severe $\mathrm{PAH}$, an understanding of the level of clinical assessment and examination required, and an awareness of the techniques that can be employed to bridge patients to transplantation. The article by CORRIS and DEGANo [13] offers an excellent summary of these elements.

The need to consider transplantation highlights how the long-term prognosis for patients with this disease remains poor, in spite of continued advances in treatment options [14]. In this context, the expectations placed on treatment by physicians and patients may differ. What constitutes treatment success for the patient? And does this expectation match that of the treating physician? What level of patient support is required beyond diagnosis and pharmacotherapy? HOWARD et al. [15] discuss these questions from both a physician and patient perspective, offering a unique insight into the essential requirements for improved patient support and decision making.

Together, the articles in this issue of European Respiratory Review highlight the multifaceted nature of PAH and the progress that has been made in managing this difficult disease, through registries and randomised controlled trials. These articles also highlight the importance that the exchange and communication of ideas amongst physicians and patients can play in recognising and moving towards new horizons in PAH treatment.

\section{Acknowledgements}

Medical writing support was provided by Nason Ma'ani (apothecom scopemedical ltd, Sevenoaks, UK), which was funded by Actelion Pharmaceuticals Ltd (Allschwil, Switzerland).

\section{References}

1 Galiè N, Corris PA, Frost A, et al. Updated treatment algorithm of pulmonary arterial hypertension. J Am Coll Cardiol 2013; 62: Suppl. 25, D60-D72.

Naeije R, Manes A. The right ventricle in pulmonary arterial hypertension. Eur Respir Rev 2014; 23: 476-487.

3 Hoeper MM, Gibbs JSR. The changing landscape of pulmonary arterial hypertension and implications for patient care. Eur Respir Rev 2014; 23: 450-457.

Ivy DD, Abman SH, Barst RJ, et al. Pediatric pulmonary hypertension. J Am Coll Cardiol 2013; 62: Suppl. 25, D117-D126. Berger RM. Pulmonary hypertension: smaller kids, smaller steps. Lancet Respir Med 2014; 2: 348-350.

Beghetti M, Berger RMF. The challenges in paediatric pulmonary arterial hypertension. Eur Respir Rev 2014; 23: 498-504. Pulido T, Adzerikho I, Channick RN, et al. Macitentan and morbidity and mortality in pulmonary arterial hypertension. N Engl J Med 2013; 369: 809-818.

8 Ghofrani HA, Galiè N, Grimminger F, et al. Riociguat for the treatment of pulmonary arterial hypertension. $N$ Engl J Med 2013; 369: 330-340.

9 Ghofrani H-A, Humbert M. The role of combination therapy in managing pulmonary arterial hypertension. Eur Respir Rev 2014; 23: 469-475.

10 Sitbon O, Jaïs X, Savale L, et al. Upfront triple combination therapy in pulmonary arterial hypertension: a pilot study. Eur Respir J 2014; 43: 1691-1697.

11 McGoon MD. Upfront triple therapy for pulmonary arterial hypertension: is three a crowd or critical mass? Eur Respir J 2014; 43: 1556-1559.

12 Sitbon O, Bertoletti L. Connective tissue disease associated with pulmonary arterial hypertension: management of a patient with severe haemodynamic impairment. Eur Respir Rev 2014; 23: 505-509.

13 Corris P, Degano B. Severe pulmonary arterial hypertension: treatment options and the bridge to transplantion. Eur Respir Rev 2014; 23: 488-497.

14 Barst RJ, Chung L, Zamanian RT, et al. Functional class improvement and 3-year survival outcomes in patients with pulmonary arterial hypertension in the REVEAL Registry. Chest 2013; 144: 160-168.

15 Howard LS, Ferrari P, Mehta S. Physicians' and patients' expectations of therapies for pulmonary arterial hypertension: where do they meet? Eur Respir Rev 2014; 23: 458-468. 